\title{
A new method for evaluating packing efficiency of particle size distribution during coal water slurry preparation
}

Heping Li

Ningxia University

Xiaoyan Chen

Ningxia University

Wanyi Liu ( $\sim$ liuwy@nxu.edu.cn )

Ningxia university https://orcid.org/0000-0002-0508-0172

Zhiqiang Wu

Ningxia University

Gang Wang

Ningxia University

\section{Research}

Keywords: probability analysis, packing efficiency, void distribution, particle size distribution, coal water slurry

Posted Date: April 7th, 2020

DOl: https://doi.org/10.21203/rs.3.rs-20660/v1

License: (1) This work is licensed under a Creative Commons Attribution 4.0 International License. Read Full License 


\title{
A new method for evaluating packing efficiency of particle size
}

\section{distribution during coal water slurry preparation}

Heping Li(li_hp@nxu.edu.cn); , Xiaoyan Chen (chenxiaoyan@nxu.edu.cn), Wanyi Liu *Email:

$$
\text { liuwy@nxu.edu.cn, Zhiqiang Wu , Gang Wang }
$$

State Key Laboratory of High-efficiency Utilization of Coal and Green Chemical Engineering, National Demonstration Center for Experimental Chemistry Education, College of Chemistry and Chemical Engineering, Ningxia University, Yinchuan 750021, P. R. China

Corresponding author Email: liuwy@nxu.edu.cn

\begin{abstract}
Particle size distribution is a key problem in preparation of coal water slurry . Due to the large number of particles and irregular accumulation of particles, how to evaluate and calculate CWS particles has become an urgent need. In this paper, the volume accumulation of particles is simplified as plane accumulation, and the particle packing gradation model based on the three-particle packing gradation and the four-particle packing gradation is constructed. Based on the classical mathematical principle, the packing voids and packing probability of 5 typical CWS particle sizes were calculated. The packing styles of $\mathrm{N}_{1} \mathrm{~N}_{2} \mathrm{~N}_{3}, \mathrm{~N}_{2} \mathrm{~N}_{3} \mathrm{~N}_{4}$ and $\mathrm{N}_{3} \mathrm{~N}_{4} \mathrm{~N}_{5}$ were evaluated and analyzed. The evaluation method of packing index based on $\Sigma \mathrm{P} \times \mathrm{S}_{\min }$ and $\Sigma \mathrm{P} \times \mathrm{S}_{\max }$ was established. The results show that the packing efficiency of particles can be quantitatively evaluated by using of cumulative calculation of voids areas and packing probabilities under different packing modes. The evaluation results are consistent to the tendency of CWS concentration. By this method, the particle size distribution of CWS can be controlled and adjusted during both wet milling processes and experimental investigations. Furthermore, the method may be used to other particle packing cases.
\end{abstract}

Key words: probability analysis; packing efficiency; void distribution; particle size distribution; coal water slurry 


\section{Introduction}

The packing property of particles refers to the inner part of particles, the arrangement of particles in space or the structural characteristics of particles. The preparation of high concentration of coal water slurry requires higher packing density. In the study of dense packing of particles, there are two major theories: continuous and discontinuous packing of particles. Continuously distributed particles are composed of particles of all sizes within a certain range of particle size, the discontinuous distribution is composed of particles representing the finite size of the range. Studies on accumulation of discrete-size particles. (Furnas 1928; Westman et al 1930; Westman 1936; Suzuki 1985) The initiator of the classical continuous theory was Andreason (Andreason 1928; Andreason 1929; Andreason 1930) , who described the actual particle distribution with equation of Gaudin-Schuhmann Golden-schutzmann .Fuller (Fuller 1906) obtained the experience curve of the most compact packing of continuous grain-size system by experiment. It is considered that the equation modulus $m$ in the range of $0.33 \sim 0.5$ has the minimum void fraction. Based on Andreason's theory, the Alfred equation is proposed by Dinger and Funk (Funk 1980; Funk1987) , and it is found that the highest accumulation rate occurs when $\mathrm{n}$ is 0.37 .Some researchers put forward the theory of inter-stage packing by analytic method, and established a new relation between the modulus $n$ and the void fraction of Gaudin and Alfred equation, and calculated the packing efficiency of any particle size distribution (Zhang et al 2002).

With the rapid development of China's coal chemical industry, the coal production process of methanol, synthetic ammonia, olefins by using of coal water slurry as gasification media is expected to use 300 million tons in the future, the amount of CWS used for combustion is about 30-60million tons annually. Therefore, coal-water slurry gasification has become the focus of chemical industry and the preparation of high concentration coal-water slurry has become an important factor in CWS applications. The minimum void accumulation model and evaluation index E provides a good method to testify the coarse particle and fine particle distribution (Tu 2013; Tu et al 2013; Tu et al 2015; Yang et al 2016). Increasing the size range of coal water slurry particles is beneficial to improving its packing efficiency, the packing efficiency is related to the particle size composition of raw materials (Chen et al 2012) . (Huang et al 2006) provide a formula for calculating the packing density of powder with continuous particle size in slurry. (Guo et al 2006; Chen 2016; Zhou 2001) put forward the discontinuous grading model and emphasize the function of the coarse particles and fine particles. (Yang et al 2015)describe a multi-peak gradation to evaluate the particle size distribution of lignite slurry after grinding with fractal theory. (Huang et al 1986) used single peak model to testify the particle size distribution with low accumulated voids. (Zhang et al 2004;Jiao 2007) have established three creative models of particle number distribution model, particle surface area distribution model and particle mass distribution model to describe the dynamic change of the particle size distribution during coal grinding. (Wang et al 2013; Wang et al 2014) calculate the particle size of Shenfu coal powder by Alfred Model.

However, sometimes it is difficult for engineers in CWS factories to understand these formulas. A 
simplified description and method for packing efficiency based on particle size distribution of CWS is needed.

\section{Experimental methods and procedures}

Fig. 1 is the experimental diagram for particles evaluation. The size composition of CWS consists of 8-mesh, 14-mesh, 40-mesh, 80-mesh and 200-mesh. Most of the size composition of qualified CWS from 8 to 14 -mesh is less than $1 \%$. Therefore, five particle sizes of 14-40 mesh, 40-80 mesh, 80-200 mesh, 200-325 mesh, <325 Mesh were selected as the research objects. According to the packing model in Fig. 2, the packing voids of particles in CWS can be calculated simply by the distribution of the above five kinds of particle sizes.

Figure 2 is the model of particle packing gradation. In Figure $2, R_{1} R_{1} R_{1}, R_{1} R_{1} R_{2}, R_{1} R_{2} R_{2}, R_{2} R_{2} R_{2}$, $R_{1} R_{1} R_{3}, R_{1} R_{2} R_{3}, R_{1} R_{3} R_{3}, R_{2} R_{3} R_{3}$ and $R_{3} R_{3} R_{3}$ are packed in a steady state with a radius of $R_{1}, R_{2}, R_{3}$. $\mathrm{R}_{1} \mathrm{R}_{1} \mathrm{R}_{1} \mathrm{R}_{1}, \mathrm{R}_{1} \mathrm{R}_{1} \mathrm{R}_{1} \mathrm{R}_{2}, \mathrm{R}_{1} \mathrm{R}_{1} \mathrm{R}_{2} \mathrm{R}_{2}, \mathrm{R}_{1} \mathrm{R}_{2} \mathrm{R}_{1} \mathrm{R}_{2}, \mathrm{R}_{1} \mathrm{R}_{1} \mathrm{R}_{1} \mathrm{R}_{3}, \mathrm{R}_{2} \mathrm{R}_{2} \mathrm{R}_{2} \mathrm{R}_{1}, \mathrm{R}_{1} \mathrm{R}_{1} \mathrm{R}_{2} \mathrm{R}_{3}, \mathrm{R}_{1} \mathrm{R}_{2} \mathrm{R}_{1} \mathrm{R}_{3}, \mathrm{R}_{2} \mathrm{R}_{2} \mathrm{R}_{2} \mathrm{R}_{2}$, $\mathrm{R}_{1} \mathrm{R}_{2} \mathrm{R}_{2} \mathrm{R}_{3}, \mathrm{R}_{1} \mathrm{R}_{2} \mathrm{R}_{3} \mathrm{R}_{2}, \mathrm{R}_{1} \mathrm{R}_{1} \mathrm{R}_{3} \mathrm{R}_{3}, \mathrm{R}_{1} \mathrm{R}_{3} \mathrm{R}_{1} \mathrm{R}_{3}, \mathrm{R}_{2} \mathrm{R}_{2} \mathrm{R}_{2} \mathrm{R}_{3}, \mathrm{R}_{1} \mathrm{R}_{2} \mathrm{R}_{3} \mathrm{R}_{3}, \mathrm{R}_{1} \mathrm{R}_{3} \mathrm{R}_{2} \mathrm{R}_{3}, \mathrm{R}_{2} \mathrm{R}_{2} \mathrm{R}_{3} \mathrm{R}_{3}, \mathrm{R}_{2} \mathrm{R}_{3} \mathrm{R}_{2} \mathrm{R}_{3}$, $R_{3} R_{3} R_{3} R_{1}, \quad R_{3} R_{3} R_{3} R_{2}, \quad R_{3} R_{3} R_{3} R_{3}$ are packed in a non-steady state with a radius of $R_{1}, R_{2}, R_{3}$.

The packing voids of particles in a unit volume is calculated and analyzed by the voids formed by particles in its cross section. The calculation procedure is as follows:

1) the particle volumes of the above five regions are defined as $V_{1}, V_{2}, V_{3}, V_{4}, V_{5}$. The mass of a single particle in the five size range is defined as $\mathrm{M}_{1}, \mathrm{M}_{2}, \mathrm{M}_{3}, \mathrm{M}_{4}$, and $\mathrm{M}_{5}$. The number of particles per unit mass in the five size ranges is defined as $\mathrm{W}_{1}, \mathrm{~W}_{2}, \mathrm{~W}_{3}, \mathrm{~W}_{4}, \mathrm{~W}_{5}$. The number of particles per unit mass cross section is defined as $\mathrm{N}_{1}, \mathrm{~N}_{2}, \mathrm{~N}_{3}, \mathrm{~N}_{4}, \mathrm{~N}_{5}$ for each of the five dimensions.

2) the probability distribution, void area distribution and cumulative void area of 10 particle grading modes under $\mathrm{N}_{1} \mathrm{~N}_{2} \mathrm{~N}_{3}$ and $\mathrm{N}_{3} \mathrm{~N}_{4} \mathrm{~N}_{5}$ packing modes were calculated according to the three-particle steady state mechanism of graded packing.

3) the probability distribution, void area distribution and cumulative void area of 21 kinds of particle grading modes under $\mathrm{N}_{1} \mathrm{~N}_{2} \mathrm{~N}_{3}$ and $\mathrm{N}_{3} \mathrm{~N}_{4} \mathrm{~N}_{5}$ packing modes are calculated according to the four-particle unsteady mechanism of graded packing.

The median of the granularity range is used as the value of the granularity range. The values of $\mathrm{D}_{1}$, $\mathrm{D}_{2}, \mathrm{D}_{3}, \mathrm{D}_{4}$ and $\mathrm{D}_{5}$ are $940 \mu \mathrm{m}, 325 \mu \mathrm{m}, 138 \mu \mathrm{m}, 60 \mu \mathrm{m}$ and $22 \mu \mathrm{m}$ respectively. As coal particles are non-spherical particles, the spherical degree of broken particles is 0.75 , so the diameter of the non-spherical particles is about 0.75 times diameter of the spherical particles. The particle diameters of the samples were $705 \mu \mathrm{m}, 244 \mu \mathrm{m}, 104 \mu \mathrm{m}, 45 \mu \mathrm{m}$ and $17 \mu \mathrm{m}$ respectively. The calculation is as follows:

$$
\begin{aligned}
& D_{1}=\frac{(14 \mathrm{mesh}+40 \mathrm{mesh})}{2}=\frac{(1430 \mu \mathrm{m}+450 \mu \mathrm{m})}{2}=940 \mu \mathrm{m} D_{1}^{\prime}=0.75 D_{1}=0.75 \times 940 \mu \mathrm{m}=705 \mu \mathrm{m} \\
& D_{2}=\frac{(40 \mathrm{mesh}+80 \mathrm{mesh})}{2}=\frac{(450 \mu \mathrm{m}+200 \mu \mathrm{m})}{2}=325 \mu \mathrm{m} \quad \begin{array}{l}
D_{2}^{\prime}=0.75 D_{2}=0.75 \times 325 \mu \mathrm{m}=243.75 \mu \mathrm{m} \approx 244 \mu \mathrm{m} \\
D_{3}^{\prime}=0.75 D_{3}=0.75 \times 138 \mu \mathrm{m}=103.5 \mu \mathrm{m} \approx 104 \mu \mathrm{m}
\end{array} \\
& D_{3}=\frac{(80 \mathrm{mesh}+200 \mathrm{mesh})}{2}=\frac{(200 \mu \mathrm{m}+76 \mu \mathrm{m})}{2}=138 \mu \mathrm{m} \quad \begin{array}{l}
D_{3}^{\prime}=0.75 D_{3}=0.75 \times 138 \mu \mathrm{m}=103.5 \mu \mathrm{m} \\
D_{4}^{\prime}=0.75 D_{4}=0.75 \times 60 \mu \mathrm{m}=45 \mu \mathrm{m}
\end{array} \\
& D_{4}=\frac{200 \mathrm{mesh}+325 \mathrm{mesh}}{2}=\frac{76 \mu \mathrm{m}+44 \mu \mathrm{m}}{2}=60 \mu \mathrm{m} \quad D_{5}^{\prime}=0.75 D_{5}=0.75 \times 22 \mu \mathrm{m}=16.5 \mu \mathrm{m} \approx 17 \mu \mathrm{m} \\
& D_{5}=\frac{325 \mathrm{mesh}+0}{2}=\frac{44 \mu \mathrm{m}}{2}=22 \mu \mathrm{m}
\end{aligned}
$$

For the purposes of the study, the particle is approximately considered to be a sphere with a volume of $1 \mathrm{~mm}^{3}$. The density of coal particles is $1.35 \mathrm{~g} / \mathrm{cm}^{3}$. The volume and mass of the coal particles in each size range are calculated as follows: 


$$
\begin{aligned}
& V_{1}=\frac{\pi D_{1}^{\prime 3}}{6}=1.83 \times 10^{-10} \mathrm{~m}^{3}, \quad \mathrm{~m}_{1}=V_{1} \times \rho=2.47 \times 10^{-4} \mathrm{~g} ; \\
& V_{2}=\frac{\pi D_{2}^{\prime 3}}{6}=7.58 \times 10^{-12} \mathrm{~m}^{3}, \quad \mathrm{~m}_{2}=V_{2} \times \rho=1.02 \times 10^{-5} \mathrm{~g} ; \\
& V_{3}=\frac{\pi D_{3}^{\prime 3}}{6}=5.81 \times 10^{-13} \mathrm{~m}^{3}, \quad \mathrm{~m}_{3}=V_{3} \times \rho=7.84 \times 10^{-7} \mathrm{~g} ; \\
& V_{4}=\frac{\pi D_{4}^{\prime 3}}{6}=4.77 \times 10^{-14} \mathrm{~m}^{3}, \quad \mathrm{~m}_{4}=V_{4} \times \rho=6.44 \times 10^{-8} \mathrm{~g} ; \\
& V_{5}=\frac{\pi D_{5}^{\prime 3}}{6}=2.35 \times 10^{-15} \mathrm{~m}^{3}, \quad \mathrm{~m}_{5}=V_{5} \times \rho=3.17 \times 10^{-9} \mathrm{~g} ;
\end{aligned}
$$

The particle size distribution of 4 CWS samples are listed in Table 1 .

Samples A, B and C are coal water slurry samples from a methanol plant in Ningxia, and Samples $\mathrm{D}$ are coal water slurry samples from a methanol plant in Inner Mongolia. The particle size of each group was the average value of $10 \mathrm{CWS}$ samples. The particle distribution parameters of samples A, B, $\mathrm{C}$ and $\mathrm{D}$ are calculated in Table 2.

\subsection{Average size}

According to the particle size distribution in Table 1, the average particle size values of $\mathrm{A}, \mathrm{B}, \mathrm{C}$ and D CWS samples are $170 \mu \mathrm{m}, 175 \mu \mathrm{m}, 170 \mu \mathrm{m}$ and $186 \mu \mathrm{m}$ respectively. The calculation is as follows:

$$
\bar{D}=\sum_{\mathrm{i}=0}^{\mathrm{n}} D_{\mathrm{i}} W_{\mathrm{i}}=D_{1} W_{1}+D_{2} W_{2}+D_{3} W_{3}+D_{4} W_{4}+D_{5} W_{5}
$$

Comparing the concentration values of A, B, C and D samples, it is found that the concentration values of D samples are $55.07 \%$, and the average size values of slurry are $186 \mu \mathrm{m}$, and the average size difference is larger than that of A, B and C. The concentration difference of A, B and C samples was $1-2 \mathrm{wt} \%$, and the average particle size difference was $5 \mu \mathrm{m}$. It is concluded that the larger the average size of CWS, the larger the number of coarse particles in CWS. The reason for this result lies in the incomplete grinding of CWS particles by steel rods in rod mills during wet overflow milling, causing more coarse particles to overflow into the finished slurry. The 14-40 mesh particle ratio of D sample in Table 1 is obviously higher than that of A, B and C sample.

\subsection{Three-particle packing gradation}

\subsubsection{Heron Formula}

The size of the void formed between particles can be expressed by the area of the triangle formed by the three central points of particles. As shown in Figure 3(a), (b) in the triangle ABC. The area of the triangle can be calculated by Heron's formula (Xia 2007). See Formula 2.

$$
\begin{aligned}
& S_{\min }=\sqrt{\mathrm{s}(\mathrm{s}-\mathrm{a})(\mathrm{s}-\mathrm{b})(\mathrm{s}-\mathrm{c})} \\
& \mathrm{s}=\frac{(\mathrm{a}+\mathrm{b}+\mathrm{c})}{2}
\end{aligned}
$$

There are 10 packing modes according to the three-particle packing gradation, which are $\mathrm{R}_{1} \mathrm{R}_{1} \mathrm{R}_{1}, \mathrm{R}_{1} \mathrm{R}_{1} \mathrm{R}_{2}, \mathrm{R}_{1} \mathrm{R}_{2} \mathrm{R}_{2}, \mathrm{R}_{2} \mathrm{R}_{2} \mathrm{R}_{2}, \mathrm{R}_{1} \mathrm{R}_{1} \mathrm{R}_{3}, \mathrm{R}_{1} \mathrm{R}_{2} \mathrm{R}_{3}, \mathrm{R}_{2} \mathrm{R}_{2} \mathrm{R}_{3}, \mathrm{R}_{1} \mathrm{R}_{3} \mathrm{R}_{3}, \mathrm{R}_{2} \mathrm{R}_{3} \mathrm{R}_{3}$ and $\mathrm{R}_{3} \mathrm{R}_{3} \mathrm{R}_{3}$ respectively.

According to the Formula (2), the calculation values of the void areas of the three-particle 
packing in $\mathrm{N}_{1} \mathrm{~N}_{2} \mathrm{~N}_{3}$ and $\mathrm{N}_{3} \mathrm{~N}_{4} \mathrm{~N}_{5}$ packing modes are shown in Table 3.

Meanwhile, the probability of $R_{1} R_{1} R_{1}, R_{1} R_{1} R_{2}, R_{1} R_{2} R_{2}, R_{2} R_{2} R_{2}, R_{1} R_{1} R_{3}, R_{1} R_{2} R_{3}, R_{2} R_{2} R_{3}, R_{1} R_{3} R_{3}$,

$\mathrm{R}_{2} \mathrm{R}_{3} \mathrm{R}_{3}$ and $\mathrm{R}_{3} \mathrm{R}_{3} \mathrm{R}_{3}$ packing modes can be calculated according to the formula (3) .

$$
\begin{aligned}
& P\left(R_{1} R_{1} R_{1}\right)=\frac{C_{N_{1}}^{3}}{C_{N}^{3}} ; P\left(R_{1} R_{1} R_{2}\right)=\frac{C_{N_{1}}^{2} \times C_{N_{2}}^{1}}{C_{N}^{3}} ; P\left(R_{1} R_{2} R_{2}\right)=\frac{C_{N_{1}}^{1} \times C_{N_{2}}^{2}}{C_{N}^{3}} ; \\
& P\left(R_{2} R_{2} R_{2}\right)=\frac{C_{N_{2}}^{3}}{C_{N}^{3}} ; P\left(R_{1} R_{1} R_{3}\right)=\frac{C_{N_{1}}^{2} \times C_{N_{3}}^{1}}{C_{N}^{3}} ; P\left(R_{1} R_{2} R_{3}\right)=\frac{C_{N_{1}}^{1} \times C_{N_{2}}^{1} \times C_{N_{3}}^{1}}{C_{N}^{3}} ; \\
& P\left(R_{2} R_{2} R_{3}\right)=\frac{C_{N_{2}}^{2} \times C_{N_{3}}^{1}}{C_{N}^{3}} ; P\left(R_{1} R_{3} R_{3}\right)=\frac{C_{N_{1}}^{1} \times C_{N_{3}}^{2}}{C_{N}^{3}} ; P\left(R_{2} R_{3} R_{3}\right)=\frac{C_{N_{2}}^{1} \times C_{N_{3}}^{2}}{C_{N}^{3}} ; P\left(R_{3} R_{3} R_{3}\right)=\frac{C_{N_{3}}^{3}}{C_{N}^{3}} ;
\end{aligned}
$$

In formula (3),

$$
\begin{aligned}
& P\left(R_{1} R_{1} R_{1}\right)+P\left(R_{1} R_{1} R_{2}\right)+P\left(R_{1} R_{2} R_{2}\right)+P\left(R_{2} R_{2} R_{2}\right)+P\left(R_{1} R_{1} R_{3}\right)+ \\
& P\left(R_{1} R_{2} R_{3}\right)+P\left(R_{2} R_{2} R_{3}\right)+P\left(R_{1} R_{3} R_{3}\right)+P\left(R_{2} R_{3} R_{3}\right)+P\left(R_{3} R_{3} R_{3}\right)=1
\end{aligned}
$$

\subsubsection{Probability distribution of three-particle packing gradation}

According to the Formula (3), the probability distribution value $\mathrm{P}$ of each packing mode can be calculated. The probability distribution of coal water slurry samples A, B, C and D is shown in Fig.4.

In Fig. $4, \mathrm{~N}_{1} \mathrm{~N}_{2} \mathrm{~N}_{3}$ is the packing probability distribution of particles with diameter $\mathrm{D}_{1}, \mathrm{D}_{2}, \mathrm{D}_{3}$ and number of particles $\mathrm{N}_{1}, \mathrm{~N}_{2}, \mathrm{~N}_{3} \cdot \mathrm{N}_{3} \mathrm{~N}_{4} \mathrm{~N}_{5}$ is the packing probability distribution of particles with diameter $\mathrm{D}_{3}, \mathrm{D}_{4}, \mathrm{D}_{5}$ and number of particles $\mathrm{N}_{3}, \mathrm{~N}_{4}, \mathrm{~N}_{5}$. As can be seen from the diagram, the probability of three particles forming $\mathrm{R}_{3} \mathrm{R}_{3} \mathrm{R}_{3}$ is the highest in the $\mathrm{N}_{1} \mathrm{~N}_{2} \mathrm{~N}_{3}$ grading model, which is $66.4 \%, 65.3 \%, 65.2 \%$ and $64.2 \%$ respectively, followed by $R_{2} R_{3} R_{3}$ packing. Under the $\mathrm{N}_{2} \mathrm{~N}_{3} \mathrm{~N}_{4}$ packing gradation mode, the probability of three particles forming $\mathrm{R}_{2} \mathrm{R}_{3} \mathrm{R}_{3}$ packing is the highest which are $38.4 \%, 37.9 \%, 38.7 \%$, $38.5 \%$ respectively, followed by $R_{3} R_{3} R_{3}$ and $R_{2} R_{2} R_{3}$. Under the $N_{3} N_{4} N_{5}$ packing gradation mode, the probability of three particles forming $\mathrm{R}_{3} \mathrm{R}_{3} \mathrm{R}_{3}$ packing is the highest which is $84.7 \%, 84.6 \%, 82.8 \%$ and $81.9 \%$ respectively, followed by $R_{1} R_{3} R_{3}$ and $R_{2} R_{3} R_{3}$. The probabilities of packing modes of $\mathrm{R}_{1} \mathrm{R}_{1} \mathrm{R}_{1}, \mathrm{R}_{1} \mathrm{R}_{1} \mathrm{R}_{2}, \mathrm{R}_{1} \mathrm{R}_{2} \mathrm{R}_{2}, \mathrm{R}_{2} \mathrm{R}_{2} \mathrm{R}_{2}, \mathrm{R}_{1} \mathrm{R}_{1} \mathrm{R}_{3}, \mathrm{R}_{1} \mathrm{R}_{2} \mathrm{R}_{3}, \mathrm{R}_{2} \mathrm{R}_{2} \mathrm{R}_{3}$ are small and their accumulative probabilities are $0.8 \%, 0.9 \%, 1.1 \%$ and $1.2 \%$ respectively.

\subsubsection{Distribution of void areas in three-particle packing gradation}

According to the calculation value $S_{\min }$ in Formula (2) and the probability value P in formula (3), the value of $\mathrm{P} \times \mathrm{S}_{\min }$ in each packing mode can be calculated. The probability distribution of three-particle packing model and the distribution of packing void areas of CWS samples A, B, C and D are shown in Fig. 5.

As can be seen from the Fig.5, in the $\mathrm{N}_{1} \mathrm{~N}_{2} \mathrm{~N}_{3}$ packing gradation mode, the contribution of $\mathrm{R}_{3} \mathrm{R}_{3} \mathrm{R}_{3}$ packing of three particles to the void area is the largest, which are $3107 \mu \mathrm{m}^{2}, 3059 \mu \mathrm{m}^{2}, 3053 \mu \mathrm{m}^{2}, 3005 \mu \mathrm{m}^{2}$ respectively, followed by $\mathrm{R}_{2} \mathrm{R}_{3} \mathrm{R}_{3}$. Under the $\mathrm{N}_{2} \mathrm{~N}_{3} \mathrm{~N}_{4}$ packing gradation mode, the contribution of $R_{2} R_{3} R_{3}$ to the packing void area is the largest, which are $613 \mu \mathrm{m}^{2}, 606 \mu \mathrm{m}^{2}, 619 \mu \mathrm{m}^{2}$ and $616 \mu \mathrm{m}^{2}$ respectively, followed by $\mathrm{R}_{2} \mathrm{R}_{2} \mathrm{R}_{3}, \mathrm{R}_{1} \mathrm{R}_{2} \mathrm{R}_{3}$ and $\mathrm{R}_{3} \mathrm{R}_{3} \mathrm{R}_{3}$. And the contribution of different CWS samples to the packing void area varies alternately. Under the $\mathrm{N}_{3} \mathrm{~N}_{4} \mathrm{~N}_{5}$ packing gradation mode, the contribution of $R_{3} R_{3} R_{3}$ to the packing void area is the largest, which are $106 \mu \mathrm{m}^{2}, 106 \mu \mathrm{m}^{2}, 104 \mu \mathrm{m}^{2}$ and $102 \mu \mathrm{m}^{2}$ respectively, followed by $\mathrm{R}_{2} \mathrm{R}_{3} \mathrm{R}_{3}$ and $\mathrm{R}_{1} \mathrm{R}_{3} \mathrm{R}_{3}$. The probabilities of packing void area of $R_{1} R_{1} R_{1}, R_{1} R_{1} R_{2}, R_{1} R_{2} R_{2}, R_{2} R_{2} R_{2}, R_{1} R_{1} R_{3}, R_{1} R_{2} R_{3}, R_{2} R_{2} R_{3}$ are small and their accumulative probabilities are $7.0 \mu \mathrm{m}^{2}, 7.2 \mu \mathrm{m}^{2}, 8.5 \mu \mathrm{m}^{2}$ and $9.0 \mu \mathrm{m}^{2}$ respectively. 


\subsubsection{Cumulative void area of three-particle packing gradation}

Based on the calculation of the probability distribution of packing gradation and the area distribution, the cumulative void area of packing gradation $\sum \mathrm{P} \times \mathrm{S}_{\min }$ is calculated in order to further analyze the difference of packing void in different granular packing states, see Formula (4) .

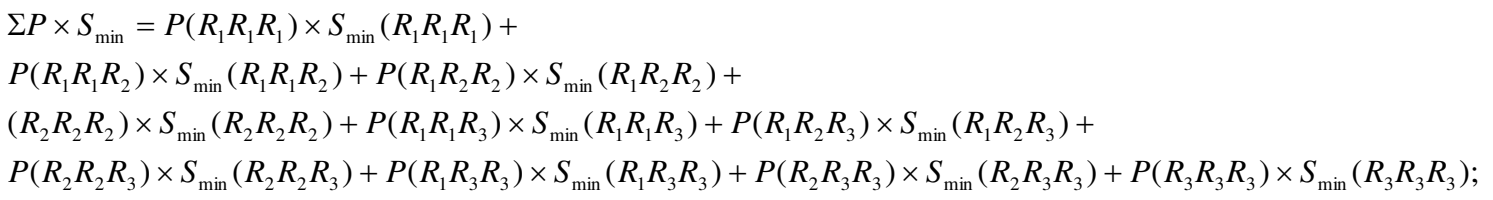

Formula (4)

The cumulative packing void areas of CWS samples A, B, C and D is shown in Fig.6.

It can be seen from Fig. 6 that under the condition of $\mathrm{N}_{1} \mathrm{~N}_{2} \mathrm{~N}_{3}$ packing gradation, the accumulative packing void areas of samples A, B, C and D are $6626 \mu \mathrm{m}^{2}, 6694 \mu \mathrm{m}^{2}, 6695 \mu \mathrm{m}^{2}$ and $6865 \mu \mathrm{m}^{2}$ respectively. The accumulated accumulation void area of D sample is the highest. Under the condition of $\mathrm{N}_{2} \mathrm{~N}_{3} \mathrm{~N}_{4}$ packing gradation, the accumulative packing voids area values of samples $\mathrm{A}, \mathrm{B}, \mathrm{C}$ and $\mathrm{D}$ are $2275 \mu \mathrm{m}^{2}, 2338 \mu \mathrm{m}^{2}, 2130 \mu \mathrm{m}^{2}, 1957 \mu \mathrm{m}^{2}$ respectively. The accumulated void area of D sample is the lowest. This result is contrary to the conclusion that the higher the packing efficiency the higher the slurry concentration. The results are consistent with the conclusion that the higher the packing efficiency the higher the CWS concentration. The reason is that $\mathrm{N}_{2} \mathrm{~N}_{3} \mathrm{~N}_{4}$ is a concentrated packing with median particle size. According to Alfred Model, the most compact packing can be achieved when fine coal powder can be completely filled into coarse coal powder. Due to the small packing voids of medium-sized pulverized coal, fine pulverized coal can not fill the voids formed by medium-sized pulverized coal, which results in the decrease of packing voids and the decrease of slurry concentration. Under the condition of $\mathrm{N}_{3} \mathrm{~N}_{4} \mathrm{~N}_{5}$ packing gradation, the accumulative packing voids area values of samples A, B, C and D are $169 \mu \mathrm{m}^{2}, 170 \mu \mathrm{m}^{2}, 172 \mu \mathrm{m}^{2}, 172 \mu \mathrm{m}^{2}$, respectively. The results are consistent with the conclusion that the higher the packing efficiency the higher the CWS concentration. In conclusion, it is feasible to use cumulative probability gap area $\sum \mathrm{P} \times \mathrm{S}_{\min }$ to evaluate the packing efficiency of CWS

\subsection{Four-particles packing gradation}

\subsubsection{Bretschneider Formula}

The size of the voids between the particles can be expressed by the area of the quadrilateral which is connected by the four central points of the particles. As shows in Figures 2(c) and (d) , the quadrangle $\mathrm{ABCD}$. The area of the quadrilateral can be calculated using Bretschneider formula (Shan 2002). See Formula 5.

$$
\begin{aligned}
& S_{\max }=\sqrt{(\mathrm{p}-\mathrm{a})(\mathrm{p}-\mathrm{b})(\mathrm{p}-\mathrm{c})(\mathrm{p}-\mathrm{d})} \\
& \mathrm{p}=\frac{(\mathrm{a}+\mathrm{b}+\mathrm{c}+\mathrm{d})}{2}
\end{aligned}
$$

According to the four particle packing gradation, there are 21 packing gradation modes, which are $R_{1} R_{1} R_{1} R_{1}, R_{1} R_{1} R_{1} R_{2}, R_{1} R_{1} R_{2} R_{2}, R_{1} R_{2} R_{1} R_{2}, R_{1} R_{1} R_{1} R_{3}, R_{2} R_{2} R_{2} R_{1}, R_{1} R_{1} R_{2} R_{3}, R_{1} R_{2} R_{1} R_{3}, R_{2} R_{2} R_{2} R_{2}$, $R_{1} R_{2} R_{2} R_{3}, R_{1} R_{2} R_{3} R_{2}, R_{1} R_{1} R_{3} R_{3}, R_{1} R_{3} R_{1} R_{3}, R_{2} R_{2} R_{2} R_{3}, R_{1} R_{2} R_{3} R_{3}, R_{1} R_{3} R_{2} R_{3}, R_{2} R_{2} R_{3} R_{3}, R_{2} R_{3} R_{2} R_{3}$, $R_{3} R_{3} R_{3} R_{1}, \quad R_{3} R_{3} R_{3} R_{2}$ and $R_{3} R_{3} R_{3} R_{3}$.

According to the Formula (5), the void areas of four-particle packing in $\mathrm{N}_{1} \mathrm{~N}_{2} \mathrm{~N}_{3}$ and $\mathrm{N}_{3} \mathrm{~N}_{4} \mathrm{~N}_{5}$ 
packing modes are shown in Table 4.

Meanwhile, the probability of $R_{1} R_{1} R_{1} R_{1}, R_{1} R_{1} R_{1} R_{2}, R_{1} R_{1} R_{2} R_{2}, R_{1} R_{2} R_{1} R_{2}, R_{1} R_{1} R_{1} R_{3}, R_{2} R_{2} R_{2} R_{1}$, $R_{1} R_{1} R_{2} R_{3}, R_{1} R_{2} R_{1} R_{3}, R_{2} R_{2} R_{2} R_{2}, R_{1} R_{2} R_{2} R_{3}, R_{1} R_{2} R_{3} R_{2}, R_{1} R_{1} R_{3} R_{3}, R_{1} R_{3} R_{1} R_{3}, R_{2} R_{2} R_{2} R_{3}, R_{1} R_{2} R_{3} R_{3}$, $R_{1} R_{3} R_{2} R_{3}, \quad R_{2} R_{2} R_{3} R_{3}, \quad R_{2} R_{3} R_{2} R_{3}, \quad R_{3} R_{3} R_{3} R_{1}, \quad R_{3} R_{3} R_{3} R_{2}$ and $R_{3} R_{3} R_{3} R_{3}$ can be calculated according to the Formula (6) .

$$
\begin{aligned}
& P\left(R_{1} R_{1} R_{1} R_{1}\right)=\frac{C_{N_{1}}^{4}}{C_{N}^{4}} ; P\left(R_{1} R_{1} R_{1} R_{2}\right)=\frac{C_{N_{1}}^{3} \times C_{N_{2}}^{1}}{C_{N}^{4}} ; \\
& P\left(R_{1} R_{1} R_{2} R_{2}\right)=P\left(R_{1} R_{2} R_{1} R_{2}\right)=\frac{1}{2} \times \frac{C_{N_{1}}^{2} \times C_{N_{2}}^{2}}{C_{N}^{4}} ; \\
& P\left(R_{1} R_{1} R_{1} R_{3}\right)=\frac{C_{N_{1}}^{3} \times C_{N_{3}}^{1}}{C_{N}^{4}} ; P\left(R_{2} R_{2} R_{2} R_{1}\right)=\frac{C_{N_{2}}^{3} \times C_{N_{1}}^{1}}{C_{N}^{4}} ; P\left(R_{1} R_{1} R_{2} R_{3}\right)=P\left(R_{1} R_{2} R_{1} R_{3}\right)=\frac{1}{2} \times \frac{C_{N_{1}}^{2} \times C_{N_{2}}^{1} \times C_{N_{3}}^{1}}{C_{N}^{4}} ; \\
& P\left(R_{2} R_{2} R_{2} R_{2}\right)=\frac{C_{N_{2}}^{4}}{C_{N}^{4}} ; P\left(R_{1} R_{2} R_{2} R_{3}\right)=P\left(R_{1} R_{2} R_{3} R_{2}\right)=\frac{1}{2} \times \frac{C_{N_{1}}^{1} \times C_{N_{2}}^{2} \times C_{N_{3}}^{1}}{C_{N}^{4}} ; P\left(R_{1} R_{1} R_{3} R_{3}\right)=P\left(R_{1} R_{3} R_{1} R_{3}\right)=\frac{1}{2} \times \frac{C_{N_{1}}^{2} \times C_{N_{3}}^{2}}{C_{N}^{4}} ; \\
& P\left(R_{2} R_{2} R_{2} R_{3}\right)=\frac{C_{N_{2}}^{3} \times C_{N_{3}}^{1}}{C_{N}^{4}} ; P\left(R_{1} R_{2} R_{3} R_{3}\right)=P\left(R_{1} R_{3} R_{2} R_{3}\right)=\frac{1}{2} \times \frac{C_{N_{1}}^{1} \times C_{N_{2}}^{1} \times C_{N_{3}}^{2}}{C_{N}^{4}} ; P\left(R_{2} R_{2} R_{3} R_{3}\right)=P\left(R_{2} R_{3} R_{2} R_{3}\right)=\frac{1}{2} \times \frac{C_{N_{2}}^{2} \times C_{N_{3}}^{2}}{C_{N}^{4}} ; \\
& P\left(R_{3} R_{3} R_{3} R_{1}\right)=\frac{C_{N_{3}}^{3} \times C_{N_{1}}^{1}}{C_{N}^{4}} ; P\left(R_{3} R_{3} R_{3} R_{2}\right)=\frac{C_{N_{3}}^{3} \times C_{N_{2}}^{1}}{C_{N}^{4}} ; P\left(R_{3} R_{3} R_{3} R_{3}\right)=\frac{C_{N_{3}}^{4}}{C_{N}^{4}} ;
\end{aligned}
$$

Formula (6)

In formula (6),

$P\left(R_{1} R_{1} R_{1} R_{1}\right)+P\left(R_{1} R_{1} R_{1} R_{2}\right)+P\left(R_{1} R_{1} R_{2} R_{2}\right)+P\left(R_{1} R_{2} R_{1} R_{2}\right)+P\left(R_{1} R_{1} R_{1} R_{3}\right)+P\left(R_{2} R_{2} R_{2} R_{1}\right)+P\left(R_{1} R_{1} R_{2} R_{3}\right)+$ $P\left(R_{1} R_{2} R_{1} R_{3}\right)+P\left(R_{2} R_{2} R_{2} R_{2}\right)+P\left(R_{1} R_{2} R_{2} R_{3}\right)+P\left(R_{1} R_{2} R_{3} R_{2}\right)+P\left(R_{1} R_{1} R_{3} R_{3}\right)+P\left(R_{1} R_{3} R_{1} R_{3}\right)+P\left(R_{2} R_{2} R_{2} R_{3}\right)+$ $P\left(R_{1} R_{2} R_{3} R_{3}\right)+P\left(R_{1} R_{3} R_{2} R_{3}\right)+P\left(R_{2} R_{2} R_{3} R_{3}\right)+P\left(R_{2} R_{3} R_{2} R_{3}\right)+P\left(R_{3} R_{3} R_{3} R_{1}\right)+P\left(R_{3} R_{3} R_{3} R_{2}\right)+P\left(R_{3} R_{3} R_{3} R_{3}\right)=1$

\subsubsection{Probability distribution of four-particle packing gradation}

According to the Formula (6), the probability distribution value $\mathrm{P}$ of each packing mode can be calculated. The probability distribution of coal water slurry samples A, B, C and D is shown in Fig.7.

As can be seen from the Fig.7, the probability of four particles forming $R_{3} R_{3} R_{3} R_{3}$ is the highest in the $\mathrm{N}_{1} \mathrm{~N}_{2} \mathrm{~N}_{3}$ grading model, which are $57.9 \%, 56.7 \%, 56.6 \%, 55.4 \%$ respectively, followed by $\mathrm{R}_{2} \mathrm{R}_{3} \mathrm{R}_{3} \mathrm{R}_{3}$ packing. Under the $\mathrm{N}_{2} \mathrm{~N}_{3} \mathrm{~N}_{4}$ packing gradation mode, the probability of four particles forming $\mathrm{R}_{2} \mathrm{R}_{3} \mathrm{R}_{3} \mathrm{R}_{3}$ packing is the highest which are $31.5 \%$, 30.6\%, 33.6\%，35.5\% respectively， followed by $R_{3} R_{3} R_{3} R_{3}, R_{2} R_{2} R_{3} R_{3}$ and $R_{2} R_{3} R_{2} R_{3}$. Under the $N_{3} N_{4} N_{5}$ packing gradation mode, the probability of four particles forming $\mathrm{R}_{3} \mathrm{R}_{3} \mathrm{R}_{3} \mathrm{R}_{3}$ packing is the highest which are $80.2 \%, 80.0 \%$, $77.8 \%$ ， $76.6 \%$ respectively， followed by $\mathrm{R}_{2} \mathrm{R}_{3} \mathrm{R}_{3} \mathrm{R}_{3}$ and $\mathrm{R}_{1} \mathrm{R}_{3} \mathrm{R}_{3} \mathrm{R}_{3}$.

\subsubsection{Distribution of void areas in four-particle packing gradation}

According to the calculation value $S_{\max }$ in Formula (5) and the probability value $\mathrm{P}$ in formula (6), the value of $\mathrm{P} \times \mathrm{S}_{\max }$ in each packing mode can be calculated. The probability distribution of four-particle packing model and the distribution of packing void areas of CWS samples A, B, C and D are shown in Fig. 8.

As can be seen from the Fig.8, the packing void area of four particles forming $R_{3} R_{3} R_{3} R_{3}$ is the highest in the $\mathrm{N}_{1} \mathrm{~N}_{2} \mathrm{~N}_{3}$ grading model, which are $6263 \mu \mathrm{m}^{2}, 6134 \mu \mathrm{m}^{2}, 6117 \mu \mathrm{m}^{2}, 5989 \mu \mathrm{m}^{2}$ respectively, followed by $R_{2} R_{3} R_{3} R_{3}$ packing. Under the $N_{2} N_{3} N_{4}$ packing gradation mode, the packing void area of four particles forming $R_{2} R_{3} R_{3} R_{3}$ packing is the highest which are $1056 \mu \mathrm{m}^{2}, 1025 \mu \mathrm{m}^{2}, 1127 \mu \mathrm{m}^{2}, 1192 \mu \mathrm{m}^{2}$ respectively, followed by $R_{2} R_{2} R_{2} R_{3}, R_{2} R_{2} R_{3} R_{3}$ and $R_{2} R_{3} R_{2} R_{3}$. And packing modes of $R_{3} R_{3} R_{3} R_{3}$, $R_{3} R_{3} R_{3} R_{1}, \quad R_{1} R_{2} R_{3} R_{3}, \quad R_{1} R_{3} R_{2} R_{3}$ also have a larger contribution to packing void area. Under the 
$N_{3} N_{4} N_{5}$ packing gradation mode, the probability of four particles forming $R_{3} R_{3} R_{3} R_{3}$ packing is the highest which are $232 \mu \mathrm{m}^{2}, 231 \mu \mathrm{m}^{2}, 225 \mu \mathrm{m}^{2}, 222 \mu \mathrm{m}^{2}$ respectively, followed by $\mathrm{R}_{2} \mathrm{R}_{3} \mathrm{R}_{3} \mathrm{R}_{3}$ and $R_{1} R_{3} R_{3} R_{3}$.The contribution of the other 18 kinds of packing modes to the packing void area is small, and the accumulative value are $25.8 \mu \mathrm{m}^{2}, 26.6 \mu \mathrm{m}^{2}, 31.3 \mu \mathrm{m}^{2}, 33.1 \mu \mathrm{m}^{2}$ respectively.

\subsubsection{Cumulative void area of four-particle packing gradation}

Based on the calculation of the probability distribution of packing gradation and the area distribution, the cumulative void area of packing gradation $\sum \mathrm{P} \times \mathrm{S}_{\max }$ is calculated in order to further analyze the difference of packing void in different granular packing states, see Formula (7) .

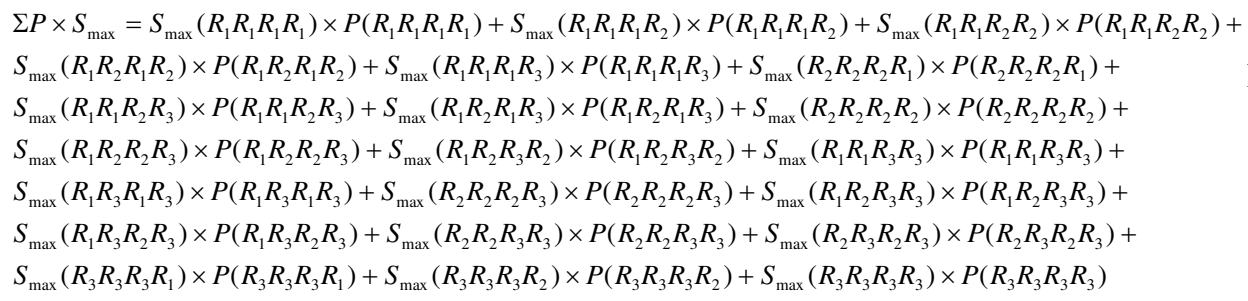

The cumulative packing void areas of CWS samples A, B, C and D is shown in Fig.9. It can be seen from Fig. 9 that under the condition of $\mathrm{N}_{1} \mathrm{~N}_{2} \mathrm{~N}_{3}$ packing gradation, the accumulative packing voids area of sample A, B, C and D are $14470 \mu \mathrm{m}^{2}, 14606 \mu \mathrm{m}^{2}, 14610 \mu \mathrm{m}^{2}$ and $14886 \mu \mathrm{m}^{2}$ respectively. The accumulated accumulation void area of $D$ sample is the highest. Under the condition of $\mathrm{N}_{3} \mathrm{~N}_{4} \mathrm{~N}_{5}$ packing gradation, the accumulative packing voids area of sample $\mathrm{A}, \mathrm{B}, \mathrm{C}$ and $\mathrm{D}$ are $351 \mu \mathrm{m}^{2}, 352 \mu \mathrm{m}^{2}, 357 \mu \mathrm{m}^{2}, 359 \mu \mathrm{m}^{2}$ respectively. The accumulative packing voids area of sample D are the highest. As can be seen from Table 1, the concentration of sample D is the lowest. The results are consistent with the conclusion that the higher the packing efficiency the higher the CWS concentration.

Under the condition of $\mathrm{N}_{2} \mathrm{~N}_{3} \mathrm{~N}_{4}$ packing gradation, the accumulative packing voids area of sample A, B, C and D are $4761 \mu \mathrm{m}^{2}, 4881 \mu \mathrm{m}^{2}, 4457 \mu \mathrm{m}^{2}, 4094 \mu \mathrm{m}^{2}$ respectively. The accumulated void area of D sample is the lowest. The reason is the same as the situation of three-particle packing gradation and it is also that the fine coal powder can not fill the voids formed by medium-size coal powder effectively, which results in the decrease of packing voids and the decrease of slurry concentration.

Therefore, it is feasible to use the larger value of the cumulative probability void area $\sum \mathrm{P} \times \mathrm{S}_{\max }$ under $\mathrm{N}_{1} \mathrm{~N}_{2} \mathrm{~N}_{3}$ and $\mathrm{N}_{3} \mathrm{~N}_{4} \mathrm{~N}_{5}$ packing modes and the smaller value of the cumulative probability void area $\sum \mathrm{P} \times \mathrm{S}_{\max }$ under $\mathrm{N}_{2} \mathrm{~N}_{3} \mathrm{~N}_{4}$ packing modes as the evaluation indexes of the CWS concentration reduction. Moreover, the results are basically consistent with the results of comparative analysis of packing voids of three-particle packing gradation. The consistency of the method is further proved.

\section{Prediction evaluation procedure for packing efficiency}

A process for predicting packing efficiency and slurry concentration based on packing gradation model is as follows:

First step: Calculate the packing void area $S_{\min }$ or $S_{\max }$.

Second step: Calculate the numbers of packing particles per unit volume according to the test value or designed values of particle size distribution.

Third step: Calculate probability of different packing modes by using of Excel softwar according to the formula of permutation and combination.

Fourth step: Calculate the values of $\sum \mathrm{P} \times \mathrm{S}_{\min }$ or $\sum \mathrm{P} \times \mathrm{S}_{\max }$ under the packing gradation of $\mathrm{N}_{1} \mathrm{~N}_{2} \mathrm{~N}_{3}, \mathrm{~N}_{2} \mathrm{~N}_{3} \mathrm{~N}_{4}$ or $\mathrm{N}_{3} \mathrm{~N}_{4} \mathrm{~N}_{5}$.

Fifth step: Adjust particle size distribution of CWS according to the value of $\sum \mathrm{P} \times \mathrm{S}_{\min }$ or $\sum \mathrm{P} \times \mathrm{S}_{\max }$.

\section{Conclusions}


(1) The packing efficiency of particles can be quantitatively evaluated by using of cumulative calculation of voids areas and packing probabilities under different packing modes. Correspondently, the CWS concentration can also be predicted by this method.

(2) The slurry concentration of CWS is closely related to its particle distribution. The size of CWS particles determines the size of the voids formed by the packing gradation of particles, and the composition of particles determines the probability of the packing gradation of CWS particles.

Under the condition of wet overflow milling, the average size of slurry calculated by weighted average can reflect the state of packing gradation of slurry particles, which is un-proportionally with the slurry concentration. The larger the average size of slurry, the lower the concentration of CWS slurry, the smaller the average size of slurry, the higher the concentration of CWS slurry.

\section{Acknowledgements}

The work is supported by the National First-rate Discipline Construction Project of Ningxia (Chemical Engineering and Technology);National Natural Science Foundation of China under Grant 21266025; and Independent Open Project of State Key Laboratory of High-efficiency Utilization of Coal and Green Chemical Engineering under Grant 2018CET04KY03.

\section{References}

[1] Furnas C.C. (1928)Relations between specific volume, voids, and size composition in systems of broken solids of mixed sizes. U.S Bureau of Mines Reports of Investigations, 12:2894.

[2]Westman,A, Hugill,H. (1930)The packing of particles. Journal of American Ceramics Society.,13(10):767-779.

[3]Westman, A, (1936)The packing of particles: empirical equations for intermediate diameter ratios. Journal of American Ceramics Society., 19:127-129.

[4]Suzuki M, Oshima T. (1985)Co-ordination number of a multi-component randomly packed bed of spheres with size distribution. Powder Technology, 44(3):213-218.

[5]Andreasen,A. (1928)The knowledge of the grinding stock, colloid-chemical supplements. 27: 349-358.

[6]Andreasen,A. (1929)Over the validity of the stokes' s law for non-spherical particles, Colloid Z, 48:175-179.

[7]Andreasen A,Andersen J(1930)Over the relationship between kornabstugung and void in products of loose particles. Colloid z.,50:217-228.

[8]Fuller W, Thompson S(1906)The laws of proportioning concrete. Transactions of the American Society of Civil Engineering.,57(2):67-143.

[9]Funk J, Dinger D, Funk J(1980)Coal grinding and particle size distribution studies for coal-water slurries at high solids content, Empire State Electric Energy Research Corporation, New York, 12.

[10]Funk J, Dinger D(1987)Modelling of particle packing and chemistry for CWM rheology,'Proceedings of the solids transport contractors review meeting, U.S.Department of Energy, Pittsburgh, 17-18 SEP.

[11] Zhang R, Liu J, Xu Z, Xie H (2002)Filling efficiency of continuous particle size distribution .Journal of China University of Mining and technology, 6:8-12.

[12] Tu. Y(2013) Optimization of particle size distribution and interfacial modification to improve the slurry concentration of Lignite. China University of Mining and technology, Beijing.

[15] Tu Y, Xu Z, Cai B, Fan X. (2013)A simple method for evaluating the effect of particle stacking and its application. China Powder technology, 19(5):53-59. 
[14] Tu Y, Xu Z, Wang W(2015) Method for evaluating packing condition of particles in coal water slurry. Powder Technology, 281:121-128.

[13] Yang X, Tu Y, Ren Y, Xu Z(2016) Optimization of packing state in brown coal water slurry based on the two-grade fractal model. Fuel,168(3):54-60.

[16] Chen Y, Wu F, Hu Y(2012) Theoretical and experimental study on increasing bulk density of powders. Coal Conversion, 35(1):37-40.

[17] Huang X, Zhu B, Guo Y, Ma B(2006)The accumulation density of continuous particle size powder in slurry. Journal of Beijing University of Aeronautics and Astronautics, 4: 461-465 +470.

[18] Guo Y, Zhu B, Huang X, Ma B,Zhu H(2006)Calculation method for packing density of powder with continuous particle size in slurry . Concrete, 2:3-5.

[19]Chen H(2016)Study on the mechanism of compound flow of coal water slurry based on discontinuous Gradation. China Coal Research Institute.

[20] Zhou X(2001)Study on particle size distribution of coal water slurry. Journal of China Coal Society, 5:557-560.

[21] Yang X, Wang N, Zheng J, Wang H(2015)Fractal theory of grinding and multi-peak grading in Lignite slurry. Coal Technology, 34(5):301-303.

[22] Huang Z, Shao J (1986)Optimization calculation of particle size distribution of pulverized coal and its application . Journal of Engineering Thermophysics, 2:169-171.

[23] Zhang S, Xia D, Wu X(2004)Fractal study on particle size distribution of coal water slurry . Thermal Science and Technology, 4:348-352.

[24] Jiao H, Xia D, Zhang S, Chen Y(2007)Granularity distribution model of coal grinding based on fractal method. Journal of Beijing University of Science and Technology, 11: 1151-1153 +1170.

[25] Wang J, Wang Y, Fang G, Zhang J, Li Z, Ju P,Xue Z, He Z, Fang S, Bai S(2013)Improving the slurryability of Shenfu coal water slurry based on Alfred Model J. Coal Science and technology, 4112:117-119.

[26] Wang J, Wang Y, Zhang J, Li Z, Ju P, He Z, Fang S, Yan L(2014) Fractal characteristics of pulverized coal and its influence on the gradation of coal water slurry. Journal of China Coal Society, 39(5):961-965.

[27] Xia X(2007)A formal proof of Heron's formula. Math bulletin, 2:60.

[28] Shan W(2002) Dictionary of mathematical inscription: Jiangsu Education Press, 376. 


\section{Figures}

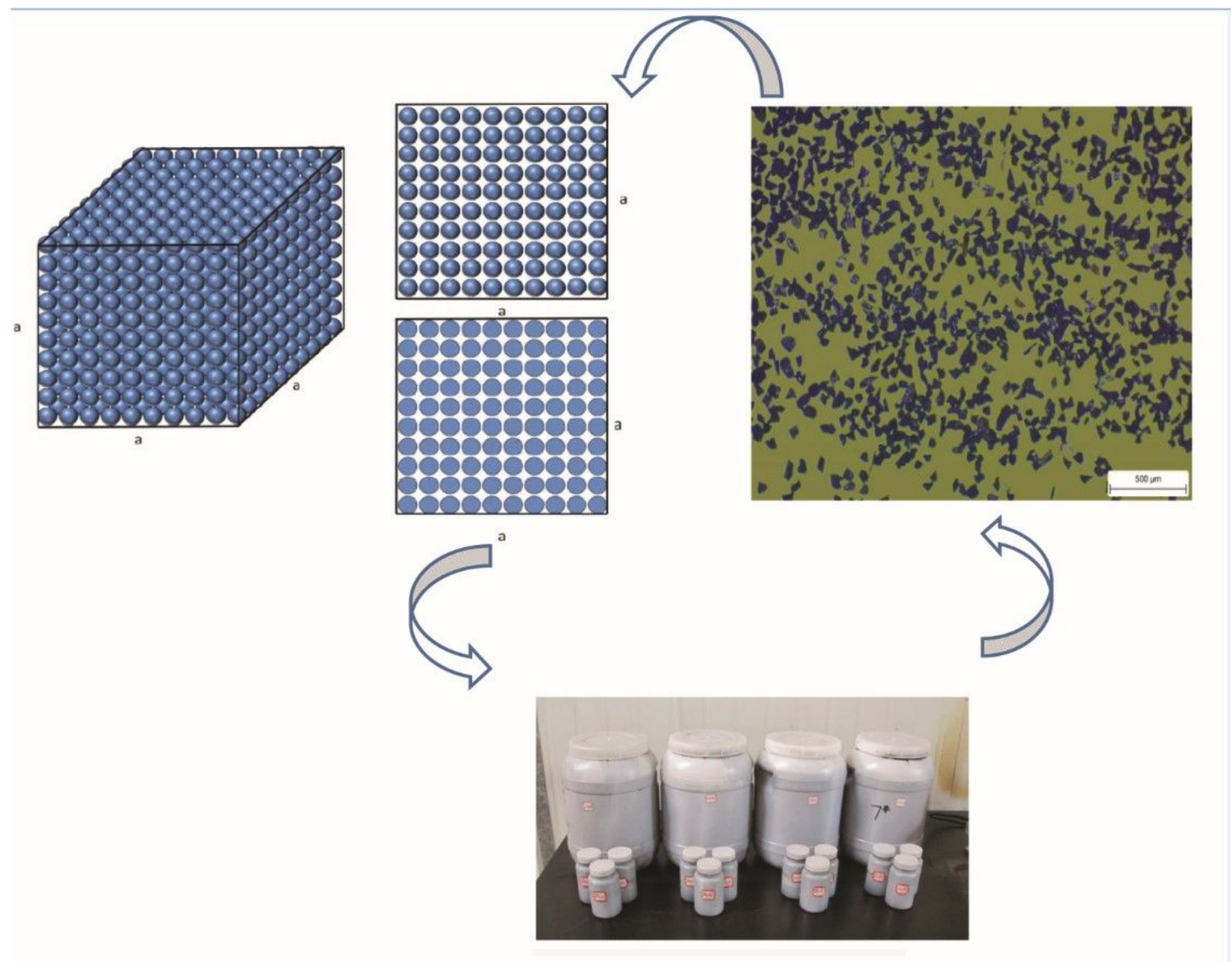

\section{Figure 1}

Fig. 1 is the experimental diagram for particles evaluation. The size composition of CWS consists of 8mesh, 14-mesh, 40-mesh, 80-mesh and 200-mesh. Most of the size composition of qualified CWS from 8 to 14 -mesh is less than $1 \%$. Therefore, five particle sizes of 14-40 mesh, 40-80 mesh, 80-200 mesh, 200325 mesh, $<325$ Mesh were selected as the research objects. According to the packing model in Fig. 2, the packing voids of particles in CWS can be calculated simply by the distribution of the above five kinds of particle sizes. 


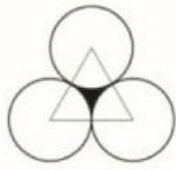

$R_{1} R_{1} R_{1}$

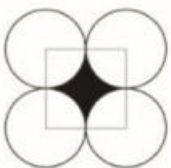

$R_{1} R_{1} R_{1} R_{1}$

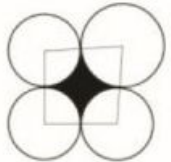

$\mathrm{R}_{2} \mathrm{R}_{2} \mathrm{R}_{2} \mathrm{R}_{\mathrm{I}}$

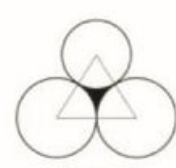

$\mathrm{R}_{1} \mathrm{R}_{1} \mathrm{R}_{2}$

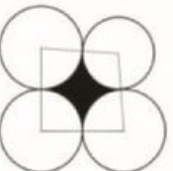

$R_{1} R_{1} R_{1} R_{2}$

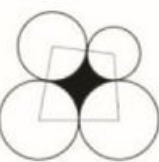

$R_{1} R_{1} R_{2} R_{3}$

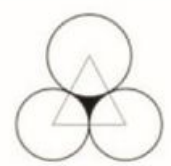

$R_{1} R_{2} R_{2}$

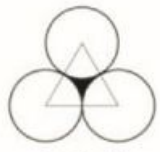

$\mathrm{R}_{2} \mathrm{R}_{2} \mathrm{R}_{2}$

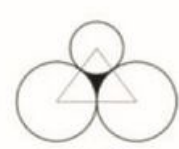

$R_{1} R_{1} R_{3}$
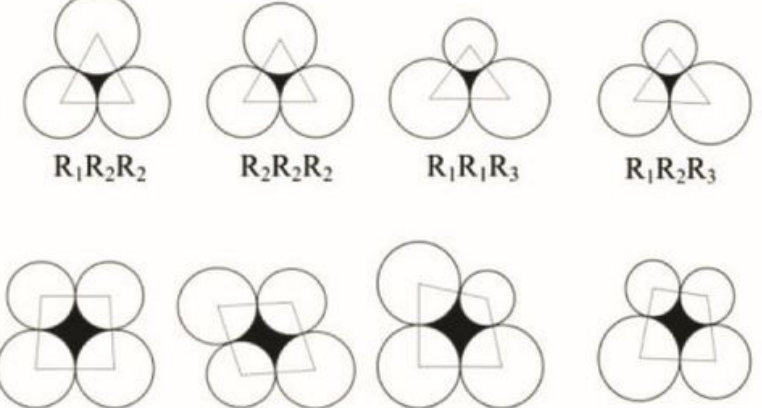

$R_{1} R_{1} R_{2} R_{2}$

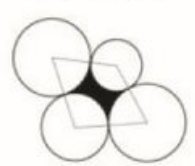

$R_{1} R_{2} R_{1} R_{3}$

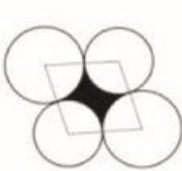

$R_{1} R_{2} R_{1} R_{2}$

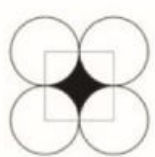

$\mathrm{R}_{2} \mathrm{R}_{2} \mathrm{R}_{2} \mathrm{R}_{2}$

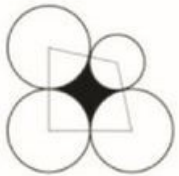

$R_{1} R_{1} R_{1} R_{3}$

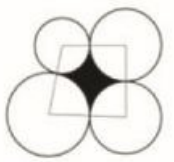

$R_{1} R_{2} R_{2} R_{3}$
$\mathrm{R}_{1} \mathrm{R}_{2} \mathrm{R}_{3}$

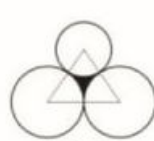

$\mathrm{R}_{2} \mathrm{R}_{2} \mathrm{R}_{3}$

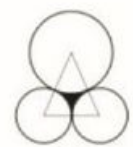

$R_{1} R_{3} R_{3}$

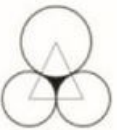

$\mathrm{R}_{2} \mathrm{R}_{3} \mathrm{R}_{3}$
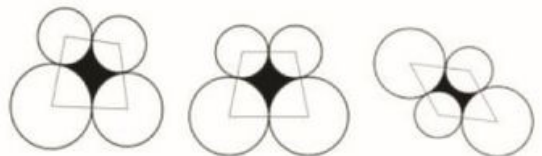

$R_{1} R_{3} R_{1} R_{3}$

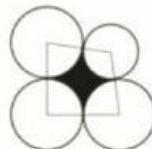

$\mathrm{R}_{2} \mathrm{R}_{2} \mathrm{R}_{2} \mathrm{R}_{3}$

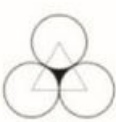

$\mathrm{R}_{3} \mathrm{R}_{3} \mathrm{R}_{3}$

Figure 2

Fig.2 is the model of particle packing gradation. In Figure 2, R1R1R1, R1R1R2, R1R2R2, R2R2R2, R1R1R3, R1R2R3, R1R3R3, R2R3R3 and R3R3R3 are packed in a steady state with a radius of R1, R2, R3.

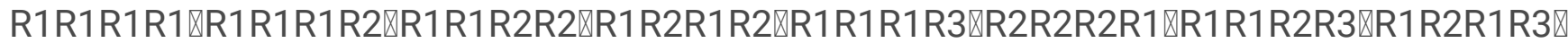

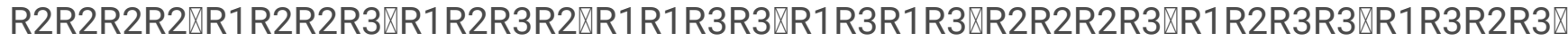
$R 2 R 2 R 3 R 3 \triangle R 2 R 3 R 2 R 3 \triangle R 3 R 3 R 3 R 1 \rrbracket R 3 R 3 R 3 R 2 \triangle R 3 R 3 R 3 R 3$ are packed in a non-steady state with a radius of $R 1, R 2, R 3$.

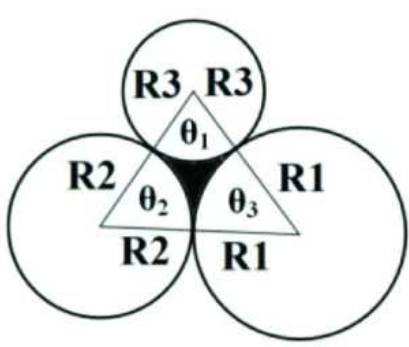

(a)

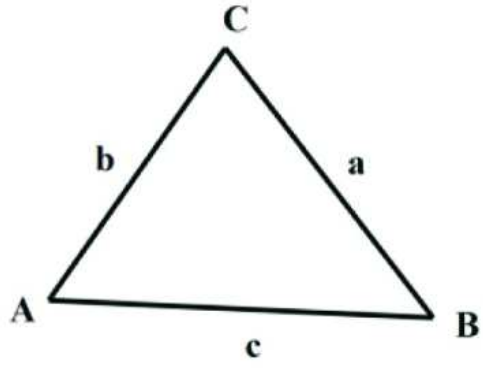

(b)

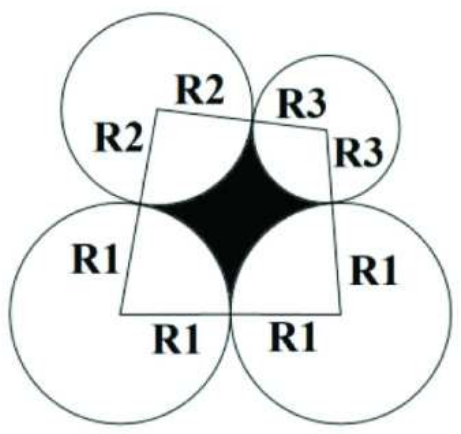

(c)

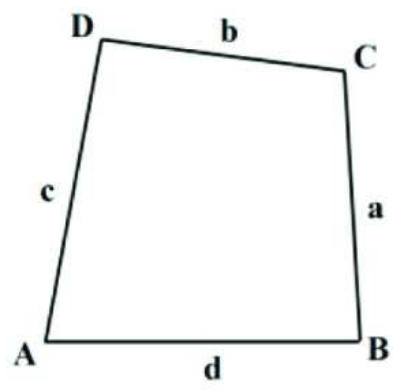

(d)

\section{Figure 3}

The size of the void formed between particles can be expressed by the area of the triangle formed by the three central points of particles. As shown in Figure 3(a) , (b) in the triangle ABC. The area of the triangle can be calculated by Heron's formula 


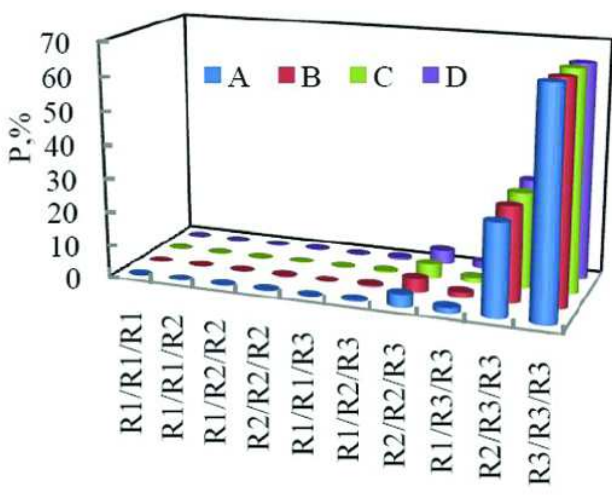

$\mathbf{N}_{1} \mathbf{N}_{2} \mathbf{N}_{3}$

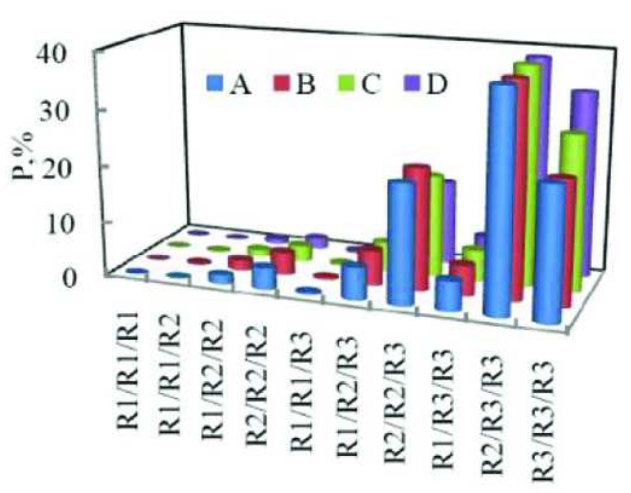

$\mathbf{N}_{2} \mathbf{N}_{3} \mathbf{N}_{4}$

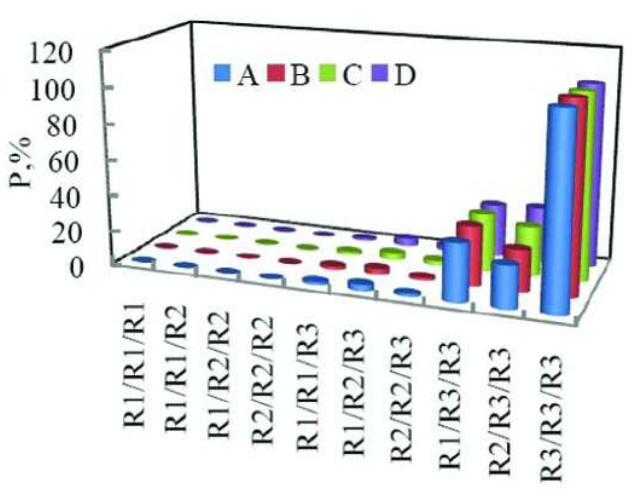

$\mathbf{N}_{3} \mathbf{N}_{4} \mathbf{N}_{5}$

\section{Figure 4}

In Fig. 4, N1N2N3 is the packing probability distribution of particles with diameter D1, D2 ,D3 and number of particles N1,N2,N3. N3N4N5 is the packing probability distribution of particles with diameter D3,D4,D5 and number of particles N3,N4,N5. As can be seen from the diagram, the probability of three particles forming R3R3R3 is the highest in the N1N2N3 grading model, which is $66.4 \%, 65.3 \%, 65.2 \%$ and $64.2 \%$ respectively, followed by R2R3R3 packing. Under the N2N3N4 packing gradation mode, the probability of

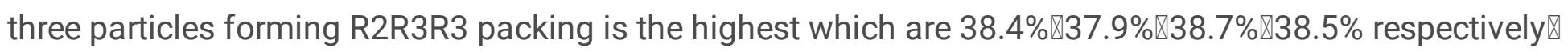
followed by R3R3R3 and R2R2R3 .Under the N3N4N5 packing gradation mode, the probability of three particles forming R3R3R3 packing is the highest which is $84.7 \%, 84.6 \%, 82.8 \%$ and $81.9 \%$ respectively $\mathbb{Z}$ followed by R1R3R3 and R2R3R3 .The probabilities of packing modes of R1R1R1هR1R1R2खR1R2R2》 $R 2 R 2 R 2 \triangle R 1 R 1 R 3 \triangle R 1 R 2 R 3 \triangle R 2 R 2 R 3$ are small and their accumulative probabilities are $0.8 \% \varangle 0.9 \% \varangle 1.1 \%$ and $1.2 \%$ respectively.

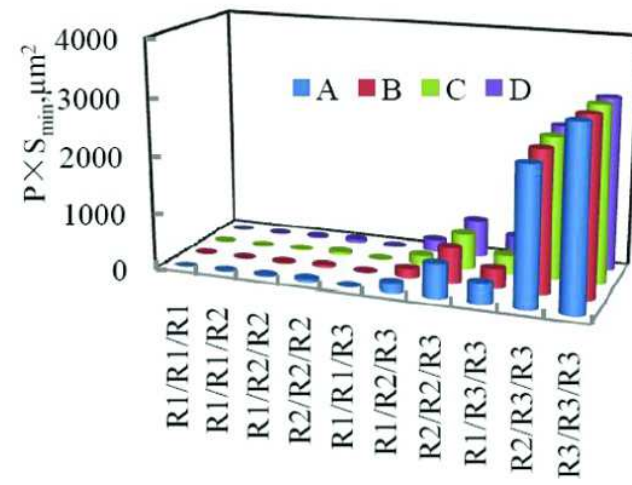

$\mathbf{N}_{1} \mathbf{N}_{2} \mathbf{N}_{3}$

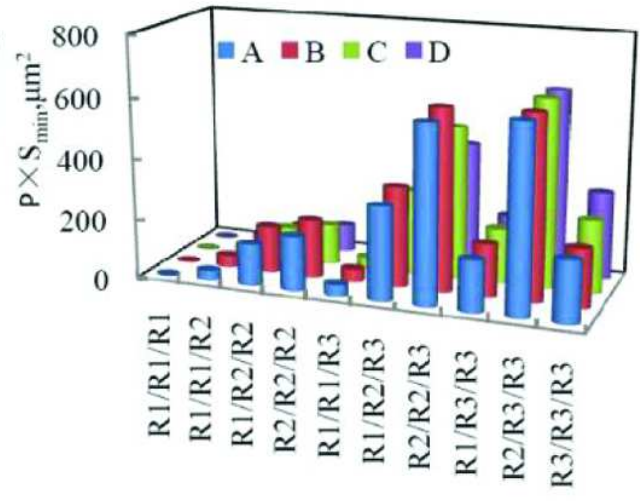

$\mathbf{N}_{2} \mathbf{N}_{3} \mathbf{N}_{4}$
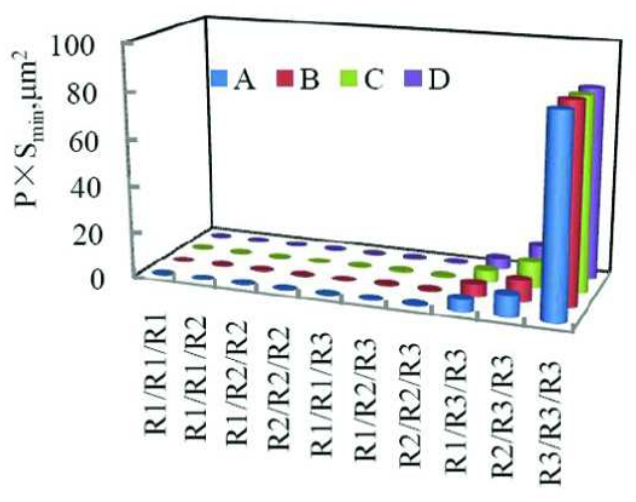

$\mathbf{N}_{\mathbf{3}} \mathbf{N}_{\mathbf{4}} \mathbf{N}_{5}$

\section{Figure 5}

As can be seen from the Fig.5, in the N1N2N3 packing gradation mode, the contribution of R3R3R3 packing of three particles to the void area is the largest, which are $3107 \mu \mathrm{m} 2,3059 \mu \mathrm{m} 2,3053 \mu \mathrm{m} 2$ , $3005 \mu \mathrm{m} 2$ respectively, followed by R2R3R3. Under the N2N3N4 packing gradation mode, the contribution of R2R3R3 to the packing void area is the largest, which are $613 \mu \mathrm{m} 2,606 \mu \mathrm{m} 2,619 \mu \mathrm{m} 2$ and 
$616 \mu \mathrm{m} 2$ respectively, followed by R2R2R3,R1R2R3 and R3R3R3.And the contribution of different CWS samples to the packing void area varies alternately. Under the N3N4N5 packing gradation mode, the contribution of R3R3R3 to the packing void area is the largest, which are $106 \mu \mathrm{m} 2,106 \mu \mathrm{m} 2,104 \mu \mathrm{m} 2$ and $102 \mu \mathrm{m} 2$ respectively, followed by R2R3R3 and R1R3R3.The probabilities of packing void area of R1R1R1区 $R 1 R 1 R 2 \rrbracket R 1 R 2 R 2 \bigotimes R 2 R 2 R 2 \rrbracket R 1 R 1 R 3 \triangle R 1 R 2 R 3 \triangle R 2 R 2 R 3$ are small and their accumulative probabilities are $7.0 \mu \mathrm{m} 2 \otimes 7.2 \mu \mathrm{m} 2 \varangle 8.5 \mu \mathrm{m} 2$ and $9.0 \mu \mathrm{m} 2$ respectively.
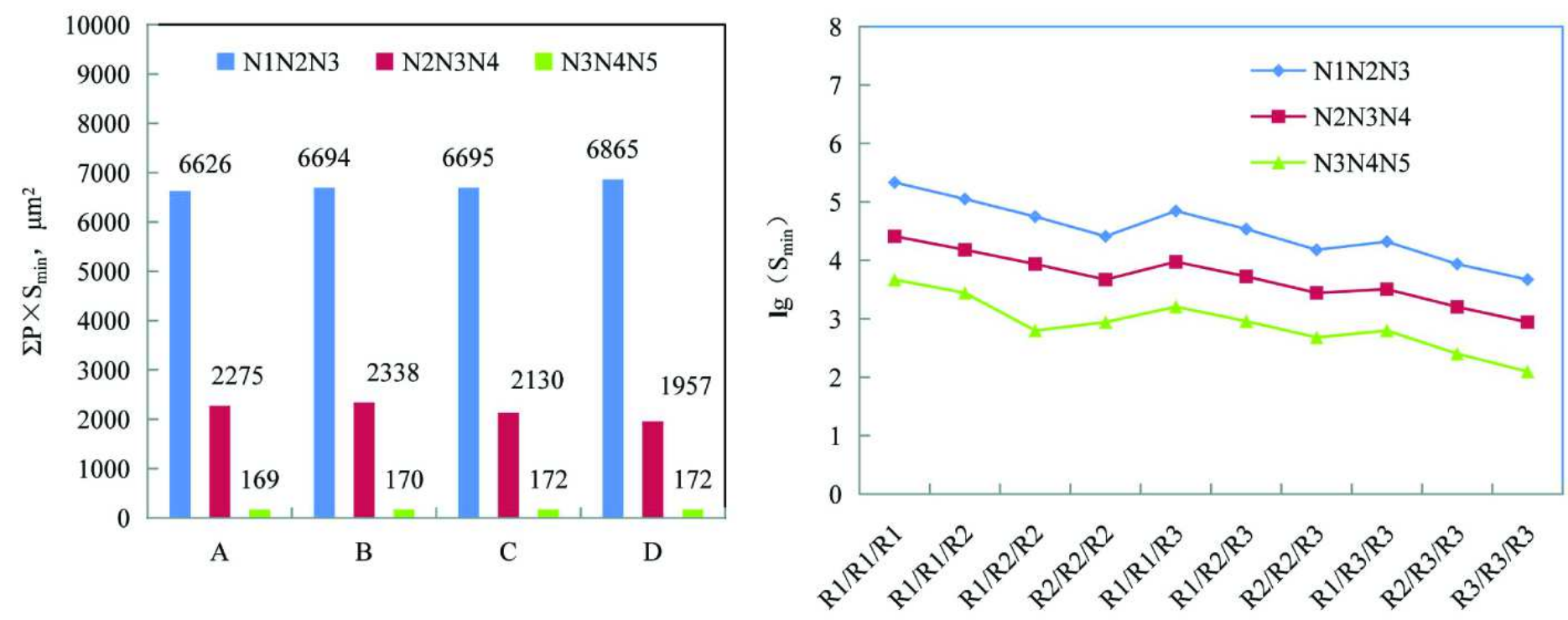

Figure 6

The cumulative packing void areas of CWS samples A, B, C and D is shown in Fig.6. 

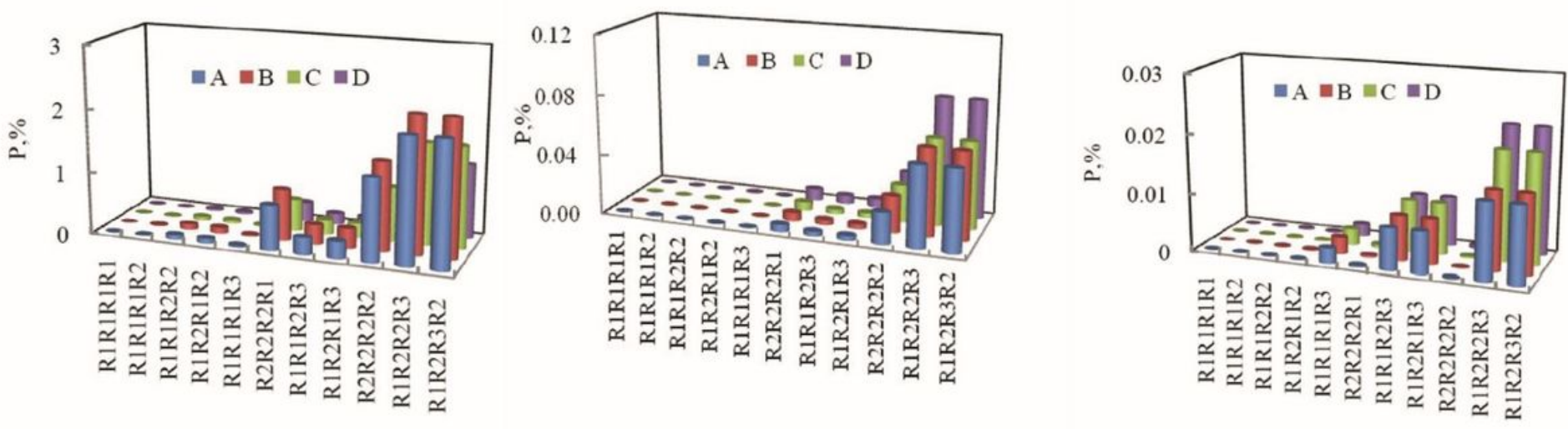

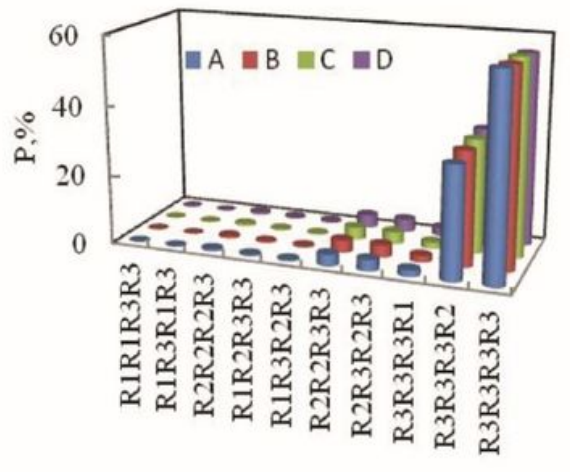

$\mathbf{N}_{1} \mathbf{N}_{2} \mathbf{N}_{3}$

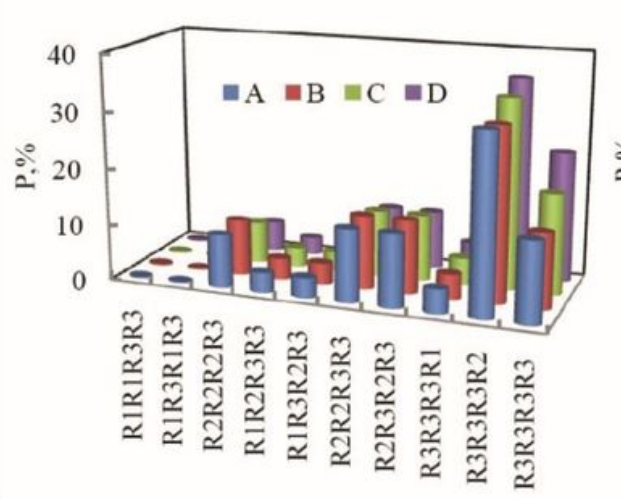

$\mathbf{N}_{2} \mathbf{N}_{3} \mathbf{N}_{4}$

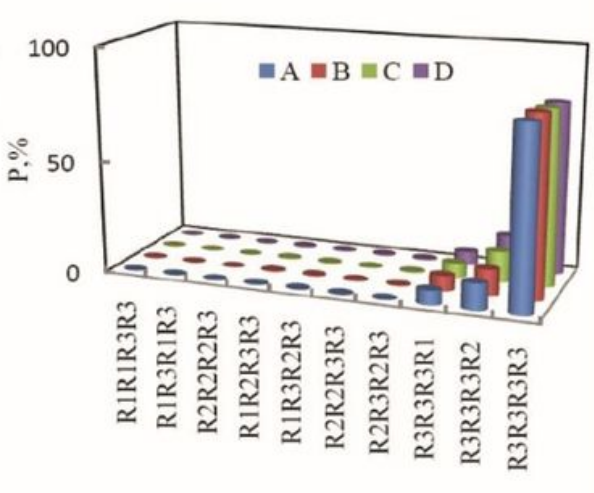

$\mathbf{N}_{3} \mathbf{N}_{4} \mathbf{N}_{5}$

\section{Figure 7}

As can be seen from the Fig.7, the probability of four particles forming R3R3R3R3 is the highest in the N1N2N3 grading model, which are $57.9 \% \otimes 56.7 \% \varangle 56.6 \% \bigotimes 55.4 \%$ respectively, followed by R2R3R3R3 packing. Under the N2N3N4 packing gradation mode, the probability of four particles forming R2R3R3R3 packing is the highest which are $31.5 \% \varangle 30.6 \% \varangle 33.6 \% \varangle 35.5 \%$ respectively $₫$ followed by R3R3R3R3,R2R2R3R3 and R2R3R2R3.Under the N3N4N5 packing gradation mode, the probability of four

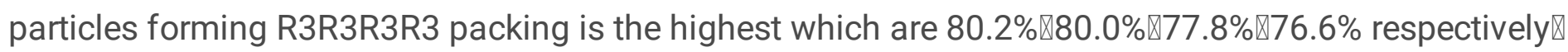
followed by R2R3R3R3 and R1R3R3R3. 

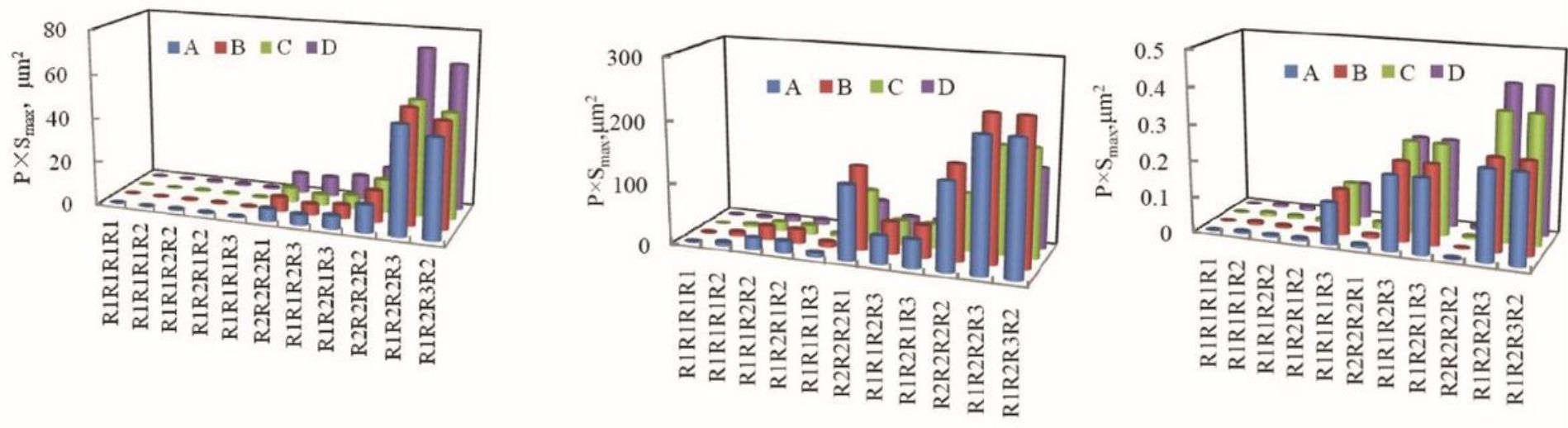

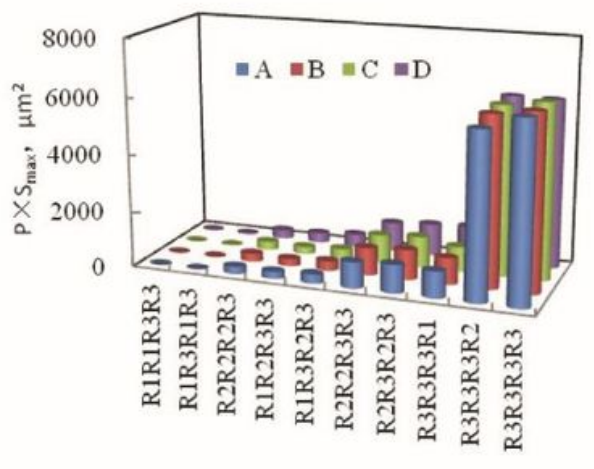

$\mathbf{N}_{1} \mathbf{N}_{2} \mathbf{N}_{3}$

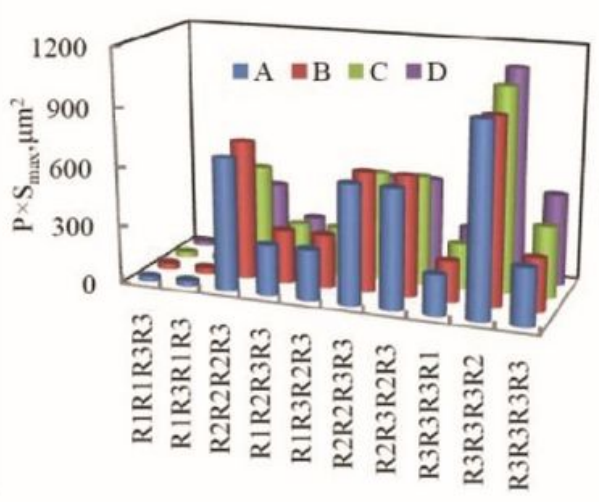

$\mathbf{N}_{2} \mathbf{N}_{3} \mathbf{N}_{4}$

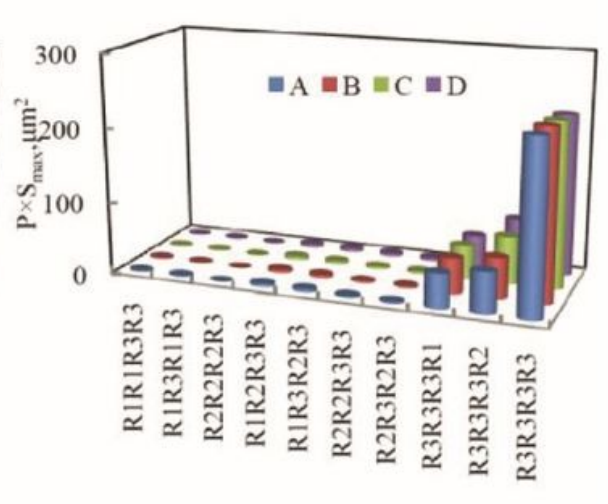

$\mathbf{N}_{3} \mathbf{N}_{4} \mathbf{N}_{5}$

\section{Figure 8}

As can be seen from the Fig.8, the packing void area of four particles forming R3R3R3R3 is the highest in the N1N2N3 grading model, which are $6263 \mu \mathrm{m} 2,6134 \mu \mathrm{m} 2,6117 \mu \mathrm{m} 2,5989 \mu \mathrm{m} 2$ respectively, followed by R2R3R3R3 packing. Under the N2N3N4 packing gradation mode, the packing void area of four particles forming R2R3R3R3 packing is the highest which are $1056 \mu \mathrm{m} 2,1025 \mu \mathrm{m} 2,1127 \mu \mathrm{m} 2,1192 \mu \mathrm{m} 2$ respectively $₫$ followed by R2R2R2R3,R2R2R3R3 and R2R3R2R3. And packing modes of R3R3R3R3》 $R 3 R 3 R 3 R 1 \otimes R 1 R 2 R 3 R 3 \triangle R 1 R 3 R 2 R 3$ also have a larger contribution to packing void area. Under the N3N4N5 packing gradation mode, the probability of four particles forming R3R3R3R3 packing is the

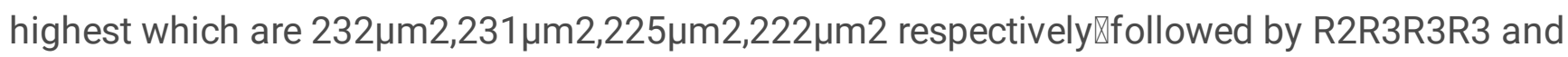
R1R3R3R3.The contribution of the other 18 kinds of packing modes to the packing void area is small, and the accumulative value are $25.8 \mu \mathrm{m} 2,26.6 \mu \mathrm{m} 2,31.3 \mu \mathrm{m} 2,33.1 \mu \mathrm{m} 2$ respectively 

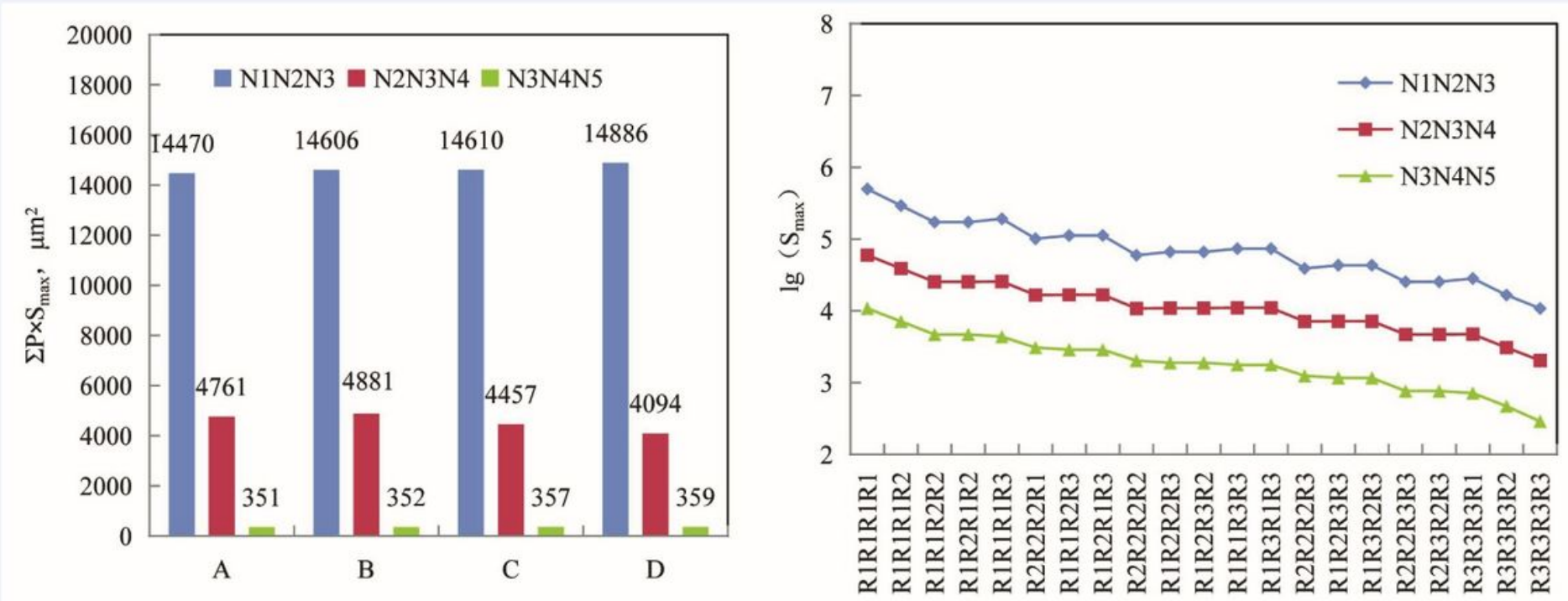

Figure 9

The cumulative packing void areas of CWS samples A, B, C and D is shown in Fig.9.

\section{Supplementary Files}

This is a list of supplementary files associated with this preprint. Click to download.

- Fig.abstract.tif 